\title{
Monitoramento ambiental e fontes de informação para a tomada de decisão estratégica: o caso dos varejos formais instalados nas imediações do shopping popular Oiapoque em Belo Horizonte
}

\author{
Paulo Henrique Oliveira \\ Mestre em engenharia de produção, na linha de pesquisa, \\ competitividade e estratégias empresariais (UFMG). \\ E-mail: peagad@yahoo.com.br
}

Wesley de Paula Neto

Graduando em administração de empresas.

E-mail: wesley.losango@oi.com.br

Fábio Henrique Roela de Oliveira

Graduando em administração de empresas.

E-mail: artico@atan.com.br

\section{Resumo}

Apresenta os resultados de uma pesquisa exploratória realizada no primeiro semestre de 2008 com micro e pequenos empresários instalados nas imediações do Shopping Popular Oiapoque, em Belo Horizonte. Para a consecução do objetivo central, que partiu da necessidade de descrever o comportamento informacional de tais empresários na tomada de decisão estratégica, optou-se pela aplicação de um questionário estruturado, com perguntas fechadas, a oito empresários da região, os quais foram escolhidos intencionalmente. Os resultados revelaram que os decisores estratégicos têm alta dependência com relação às fontes de informação "consumidores que compram no Oiapoque, fornecedores e funcionários da própria empresa e os concorrentes que atuam dentro do Shopping Popular" na tomada de decisão. Por outro lado, as fontes escritas como o jornal do bairro, relatórios setoriais publicados por entidades do comércio e os comércios não concorrentes e seus respectivos funcionários e fornecedores não apresentaram resultados significativos em termos de dependência para a tomada de decisão estratégica.

\section{Palavras-chave}

Fontes de informação. Tomada de decisão estratégica. Varejo formal.

Environmental monitoring and information sources for strategic decision making: the case of formal retailers installed near the popular shopping Oiapoque in Belo Horizonte

\section{Abstract \\ This article presents the results of a survey carried out in the first half of 2008 with micro and small entrepreneurs installed near the Popular Shopping Oiapoque in Belo Horizonte. For reaching the central objective and the needs to describe the informational behavior of these entrepreneurs in making a decision, a well structured questionnaire was sent to eight entrepreneurs chosen for this purpose. The results show that the strategic decision makers are highly dependent on information sources as "consumers who buy at Oiapoque, suppliers and employees of their own enterprise and competitors working in the "Popular Shopping". The written sources, as for instance, the outskirts newspaper, sectoral reports put out by commercial entities, non- competitor commerce and their respective employees and suppliers do not present significant results in regard to making a strategic decision. \\ Keywords}

Sources of information. Strategic decision making. Formal retailers.

\section{INTRODUÇÃO}

Para muitas organizações o século XXI chega com grandes incertezas, ameaças e oportunidades. Entra-se em uma era determinada pela grande volatilidade do ambiente competitivo, na qual aqueles que estiverem mais adaptados terão maiores chances de sobreviver e de crescer nesse ambiente em constante e crescente mutação (AGUILAR, 1967; DAFT, 2002; MINTZBERG, 2003). E, no contexto dos micros e pequenos empreendimentos instalados nas imediações dos Shoppings Populares, essa situação parece não ser muito diferente. $\mathrm{O}$ aumento da competição predatória nessas localidades tem exigido nova postura gerencial e estratégica por parte dos empreendedores formais instalados nas imediações do Shopping Oiapoque.

Surgidos no Brasil no início da década de 1990, tradicionalmente conhecidos como um feirão de ofertas, os Shoppings Populares têm funcionado geralmente em fábricas desativadas ou armazéns abandonados, usados como alternativas de algumas prefeituras para a revitalização das regiões centrais, remanejando o comércio informal das vias públicas para um espaço fechado, buscando-se contribuir para melhor organização, limpeza e segurança dos centros urbanos. Segundo Neto (1998):

Nesses locais, centenas de comerciantes montam suas lojas e oferecem descontos que vão de 10\% a 50\% em relação ao que se cobra em lojas comuns. É um paraíso para os consumidores vorazes. Ali eles podem comprar aparelhos de som, videocassetes, televisores made in Coréia ou Hong Kong, perfume francês, pasta de dente americana e vodca russa. Também há produtos nacionais, como malhas de lã, calças jeans, jaquetas de couro, roupas infantis, sapatos, bolsas e até grinaldas para noivas. Tudo com os mesmos descontos dos importados (NETO, 1998).

Em Belo Horizonte, os Shoppings Populares surgiram como uma forma de organizar o comércio da região central da capital mineira. Para Albuquerque (2007), esses empreendimentos são centros de compras que 
concentram comerciantes informais mediante pagamento de taxas de administração e aluguel de espaços físicos para vendas. Para os comerciantes, o aluguel é vantajoso, pois custa geralmente de 150 a 300 reais por metro quadrado, enquanto uma loja em um shopping comum custa por metro quadrado 2.000 reais nos mais baratos (NETO, 1998). As mercadorias são importadas diretamente da Coréia, da China ou de Taiwan, não tendo, nenhum tipo de intermediação. Esse tipo de comercio existe também nos Estados Unidos, e são chamados de outlets e vendem ponta de estoque. Os produtos vendidos nestes locais têm preços muito abaixo dos seus concorrentes formais, e muitos empresários locais têm questionado essa diferença gritante de preços. Albuquerque (2007), por exemplo, argumenta que a carga tributária dos produtos vendidos no mercado legal torna a acessibilidade do consumidor a determinados produtos extremamente restrita. É nesse contexto que o mercado informal - ou "pirata" - surge para atender aos anseios do consumidor que busca os mais variados produtos geralmente importados - a preços mais acessíveis

E é neste contexto de profunda turbulência e transformação competitiva que a presente pesquisa investiga o comportamento informacional dos micros e pequenos empreendedores instalados nas proximidades do Shopping Popular Oiapoque em Belo Horizonte. Nos últimos anos, a região tem enfrentado um crescimento da competição predatória por parte dos pequenos comércios instalados no interior do shopping em questão, os quais têm praticado preços muito abaixo daqueles encontrados nos comércios formais que atuam em suas imediações (ALBUQUERQUE, 2007). Tal fenômeno tem colocado em risco a capacidade de sobrevivência e de crescimento desses empreendedores. Conforme um empreendedor relatou durante a fase de coleta de dados, "a concorrência nesta região é muito desleal. Eu já quebrei quatro vezes. Já não sei mais o que fazer. Se continuar desse jeito, vou quebrar novamente". Essa consideração expõe o problema sério que enfrenta grande parte dos comércios daquela região.

Dessa maneira, para a consecução do objetivo principal optou-se por uma pesquisa exploratória, a qual se preocupou em levantar questões e sugestões a serem investigadas e aprofundadas por futuras pesquisas, pois o tema é bastante interessante e necessita de um estudo mais abrangente e aprofundado sobre a situação e as condições dos empreendimentos instalados naquela região.

Na coleta de dados foi utilizado um questionário fechado, o qual foi aplicado a oito empreendedores, escolhidos intencionalmente a partir dos seguintes critérios: proximidade com o Shopping Popular Oiapoque; disponibilidade de tempo dos pesquisadores e tamanho e aparência da loja, observando-se, inclusive, o fluxo de pessoas (clientes) que entravam na loja no período da coleta. Assim, as lojas que apresentaram melhor aparência estética (interna e externa), fluxo constante de clientes e maior proximidade com o Shopping em questão foram selecionadas a partir da percepção dos pesquisadores. Por último, por ser uma pesquisa predominantemente quantitativa, técnicas estatísticas foram utilizadas para o processamento dos dados.

É importante ressaltar que, apesar da grande importância do tema em questão, este estudo não teve a pretensão de esgotar o tema em questão, mas sim trazer à tona a necessidade de melhor compreensão do comportamento informacional dos micro e pequenos empresários instalados nas imediações de um grande shopping popular da região central de Belo Horizonte: o Shopping Oiapoque.

\section{MONITORAMENTO AMBIENTAL, FONTES DE INFORMAÇÃO E TOMADA DE DECISÃO ESTRATÉGICA}

A atividade de monitoramento ambiental (environmental scanning) normalmente é entendida na literatura como a aquisição e o uso da informação sobre eventos, tendências e relacionamentos que acontecem no ambiente externo da organização (AGUILAR, 1967; AUSTER; CHOO, 1993). Aguilar (1967), por exemplo, argumenta que as organizações monitoram seus ambientes a fim de entender as mudanças das forças externas que afetam o seu funcionamento na tentativa de desenvolver respostas rápidas e precisas para manter posições privilegiadas nos mercados em que atuam ao longo do tempo. Sutton (1988) defende a necessidade de se manter um processo de monitoramento ambiental contínuo para ajudar os gestores a evitar surpresas, identificar ameaças e prover novas oportunidades de negócios, além de proporcionar a sustentabilidade das vantagens competitivas mediante atividades de planejamento de curto e longo prazos. Na visão de Auster e Choo (1993), a capacidade de adaptação organizacional é variável dependente das mudanças que acontecem em seu ambiente externo e está diretamente relacionada à sua base de conhecimentos sobre esse ambiente e de como tais mudanças são interpretadas, constituindo-se, segundo o autor, em um modo primário de aprendizagem organizacional. 
Em termos estruturais, o ambiente externo pode ser compreendido a partir da sua segmentação em dois níveis: ambiente geral e ambiente de tarefas (MINTZBEG, 2003; DUNCAN, 1972; DAFT, 2002). Ao se analisar a empresa como um sistema aberto (KATZ; KAHN, 1970, MILES; SNOW, 1978), é preciso aceitar que toda a organização opera dentro de um ambiente mais amplo, que inclui indivíduos, grupos, outras organizações e forças tecnológicas e sociais maiores, todas com um impacto potencial poderoso sobre o desempenho da organização (MINTZBERG, 2003). Especificamente, o ambiente inclui mercados (clientes), fornecedores, órgãos governamentais e reguladores, condições tecnológicas, sindicatos, concorrentes, instituições financeiras e grupos de interesse especial que podem afetar e serem afetados diretamente pela organização quando esta busca atingir os seus objetivos e metas de longo prazo (HITT et alii, 2003).

Para Nadler, Gerstein e Shaw (1993), o ambiente pode afetar o funcionamento da organização de três maneiras distintas: (i) por meio da exigência de novos produtos ou serviços; (ii) por meio de limitações à ação organizacional como escassez de capital ou de tecnologia; (iii) por meio da oferta de oportunidades a serem exploradas pela organização. Mintzberg (2003) propõe que o ambiente externo de uma organização ainda pode ser compreendido mediante análise de quatro dimensões básicas:

1. estabilidade: o ambiente de uma organização pode variar do estável até o dinâmico. Uma variedade de fatores pode tornar o ambiente dinâmico, como, por exemplo, governos instáveis, mudanças imprevisíveis nas estratégias dos concorrentes e na economia ou nas demandas da sociedade. É importante ressaltar que dinâmico nesse contexto significa imprevisível, e não variável, pois variabilidade pode ser previsível;

2. complexidade: o ambiente de uma organização pode variar desde o simples até o complexo. A dimensão complexidade afeta a estrutura mediante o entendimento do trabalho a ser feito;

3. diversidade de mercados: os mercados de uma organização podem variar de um integrado (ou homogêneo) até um diversificado (ou heterogêneo). A diversidade de mercado pode resultar de ampla faixa de clientes, de produtos e serviços, ou de áreas geográficas, nas quais os resultados são comercializados. A diversidade de mercado afeta a estrutura mediante a diversidade do trabalho a ser feito;
4. hostilidade: o ambiente de uma organização pode variar de magnânimo a hostil. A hostilidade é influenciada pela competição, pelas relações das organizações com sindicatos, governo e outros grupos externos e pela sua disponibilidade de recursos. Certamente, os ambientes hostis são caracteristicamente dinâmicos, no entanto a hostilidade externa tem efeito sobre a organização, mediante a velocidade da resposta necessária.

Essas dimensões configuram um aspecto interessante na análise sistêmica da organização. Seja qual for a dimensão, a organização deve buscar informações para alimentar suas estratégias que promovam um ajuste eficiente e eficaz entre os seus componentes e as variáveis ambientais (OLIVEIRA et alii, 2006; MINTZBERG, 2003). Dessa forma, é importante que a organização mantenha um sistema de monitoração ambiental contínuo para prever possíveis oportunidades e ameaças à sobrevivência e crescimento organizacional nos mercados em que atuam. A figura 1 ilustra o ambiente e as suas dimensões.

Como se pode perceber, o ambiente de negócios pode afetar o modo de como as organizações funcionam e são administradas. Desde os estudos de Chandler (1962) sobre ambiente e estratégia organizacional até os dias de hoje, percebe-se que os temas estratégia empresarial e ambiente externo ainda assumem grande relevância para os meios acadêmicos e empresariais. Motta (1982), por exemplo,

\section{FIGURA 1}

O ambiente externo e a visão da organização como um sistema aberto

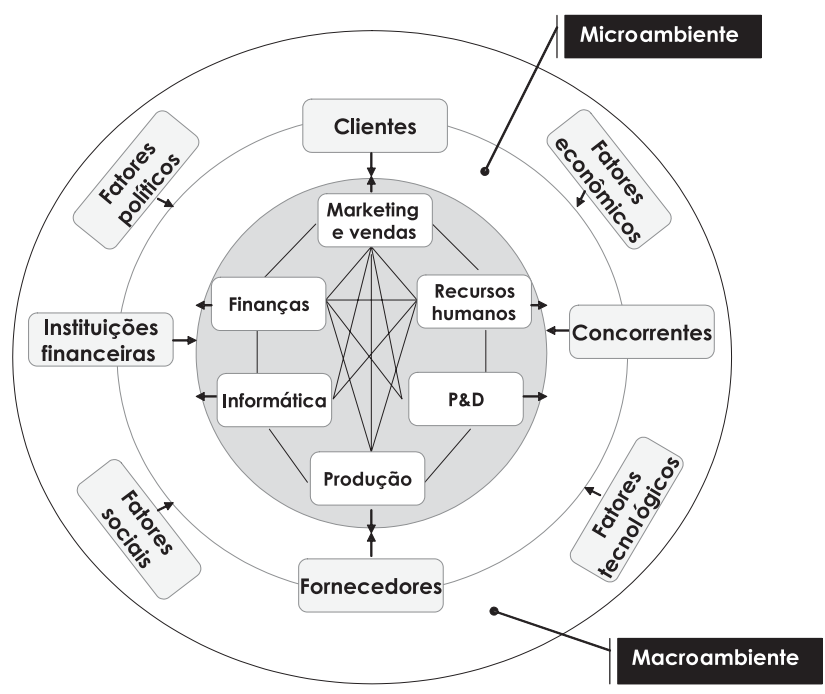

Fonte: adaptado de Mintzberg (2003), Daft (2002) e Duncan (1972). 
tem defendido a tese de que as organizações precisam manter um processo de aperfeiçoamento contínuo dos seus processos de planejamento na tentativa de criar estratégias para evitar surpresas e ameaças, além de prover as oportunidades de negócios que venham a surgir nesse ambiente cada vez mais complexo, dinâmico e imprevisível. Davenport e Prusak (1998), porém, apostam no conhecimento organizacional como fonte de vantagem competitiva no atual contexto ambiental. Nonaka e Takeushi (1997) e Choo (2003) também têm abordado o tema conhecimento como instrumento potencializador do processo de tomada de decisão estratégica e geração de vantagens competitivas continuadas. Esses autores defendem a tese de que as organizações precisam usar estrategicamente o conhecimento de seus colaboradores caso desejem sobreviver em ambientes cada vez mais incertos, turbulentos e hostis, visão compartilhada por Drucker (1995; 1999). Para esse autor, as organizações precisam se converter o mais rápido possível em organizações da informação e do conhecimento.
Com o crescimento em complexidade e dinamicidade dos ambientes competitivos, estudos sobre estratégias têm se proliferado nos meios acadêmicos e empresariais. Fatos como globalização, avanços tecnológicos e mudanças sociais, econômicas e políticas têm justificado a sua importância e proporcionado o aparecimento e disseminação de temas relacionados com a gestão da informação e do conhecimento, aprendizagem organizacional, inteligência competitiva, vantagens competitivas sustentáveis, monitoramento ambiental nessa incipiente economia da informação e do conhecimento.

Em termos teóricos e históricos, é consenso na literatura que o conceito de estratégia tem as suas origens na área militar e a sua adoção posterior no ambiente de negócios. Para melhor contextualização e esclarecimento do termo estratégia, algumas definições e suas características principais são apresentadas no quadro 1 .

\section{QUADRO 1}

Estratégia: definições e características principais

\begin{tabular}{c|l}
\hline \multicolumn{1}{c|}{ Autores } & \multicolumn{1}{c}{ Características básicas do termo estratégia } \\
\hline \multirow{2}{*}{ GEORGE STEINER } & $\begin{array}{l}\text { - É o que os administradores de topo fazem de grande importância para a organização. } \\
\text { - Refere-se a decisões básicas de direcionamento (missão) e as ações importantes e necessárias } \\
\text { para a sua realização. }\end{array}$ \\
\hline - Deve responder à seguinte questão: o que a organização deveria estar fazendo?
\end{tabular}

Fonte: Steiner (1979), Mintzberg (1994), Andrews (1980) e Porter (1980). 
Em termos conceituais, a estratégia ainda pode ser entendida como:

Um conceito cuja raiz remonta à Grécia Antiga, onde a palavra strategeia se referia à arte de ser general, liderar exércitos e destruir inimigos [...] Refere-se ao caminho que a organização segue para conseguir sobreviver. É uma busca deliberada por um plano de ação que permita desenvolver e, continuamente, ajustar uma vantagem competitiva da organização sobre seus concorrentes. A essência de sua formulação é escolher como a organização pretende ser diferente (SOBRAL; PECI, 2008, p.140).

Um plano de ação abrangente que identifica as diretrizes de longo prazo para uma organização e utiliza recursos para atingir metas com vantagem competitiva sustentável (SCHERMERHORN, 2007, p. 193).

Um plano de como chegar lá (KOTLER, 2000, p.102).

Plano amplo e geral desenvolvido para atingir objetivos de longo prazo. A estratégia organizacional pode abranger, e geralmente o faz, várias áreas organizacionais diferentes, como marketing, finanças, produção, pesquisa e desenvolvimento e relações públicas. Ela dá ampla direção à organização (CERTO, 2003, p.150).

De maneira geral, a estratégia depende de como a organização coleta, armazena, processa, recupera e disponibiliza a informação (HAMBRICK, 1982; PORTER, 1980; HITT et alii, 2003). A informação é um recurso valioso para o processo de tomada de decisão organizacional. A escolha adequada de fontes de informação é fator crítico para a eficiência e a eficácia das decisões tomadas (SIMON, 1965; CHOO, 2003). As fontes de informações podem ser classificadas de diversas maneiras e critérios diferentes.

Sutton (1988), em uma pesquisa realizada com gerentes norte-americanos, identificou os principais tipos de fontes normalmente utilizadas pelos gerentes em seus processos decisórios e que estão reproduzidos a seguir:

a. fontes internas: setores de vendas, de pesquisa mercadológica, de planejamento, de engenharia, de compras, análise de produtos concorrentes, exempregados de concorrentes;

b. contatos diretos com o setor de negócios: clientes, encontros, demonstrações de vendas, distribuidores, fornecedores, associações comerciais, consultores, varejistas, empregados dos concorrentes, agências de publicidade;

c. informações publicadas: periódicos do setor, material promocional das empresas, relatórios anuais, relatórios de analistas financeiros, periódicos financeiros, discursos dos gerentes, periódicos de negócios, jornais nacionais e locais, diretórios, publicações governamentais;

d. outras fontes: analistas financeiros, bases de dados eletrônicas, bancos de investimentos e comerciais, anúncios.

Nesta mesma linha de pesquisa, Choo (1994), apud Barbosa (2002), realizou um estudo no qual foram identificados quatro tipos de fontes de informação que são bastante utilizadas em pesquisas acadêmicas. Os resultados encontrados pela pesquisa de Choo revelaram que a inteligência é gerada a partir da utilização de quatro fontes de informações principais: externas pessoais e impessoais; internas - pessoais e impessoais.

Analisados os conceitos e características sobre ambiente, estratégia e fontes de informação, percebe-se que o atual contexto competitivo tem demandado nova postura estratégica das organizações. Modelos tradicionais já não respondem mais com tanta eficácia como no passado. Atualmente, os fatores imprevisibilidade e complexidade ambientais têm demandado posturas mais flexíveis, criativas e inovadoras por parte dos gestores e das organizações como um todo e, para tanto, torna-se necessário que eles mantenham um processo de monitoramento contínuo de seu ambiente competitivo, identificando e selecionando fontes de informações úteis e confiáveis para a tomada de decisão estratégica que aumentem as possibilidades de sobrevivência e o crescimento organizacional nos mercados em que atuam ao longo do tempo.

\section{METODOLOGIA}

Para a análise do comportamento informacional e estratégico dos empreendedores instalados nas imediações do Shopping Popular Oiapoque, optou-se pela realização de uma pesquisa do tipo exploratória, em que, segundo Collins e Hussey (2005, p.24),

o foco é obter insights e familiaridade com a área do assunto para investigações mais rigorosas num estágio posterior. [...] Os dados compilados costumam ser quantitativos e técnicas estatísticas são geralmente utilizadas para resumir as informações. 
A escolha da pesquisa exploratória derivou-se da necessidade de se averiguar, por meio de um levantamento quantitativo e análises estatísticas, a situação atual das práticas de monitoramento do ambiente competitivo (comportamento informacional) exercido por tais empreendedores da região, buscandose identificar questões e/ou hipóteses para futuras pesquisas sobre o tema em questão.

$\mathrm{Na}$ coleta de dados, foi utilizado um questionário estruturado, com perguntas fechadas, o qual foi aplicado a oito empresários da região. Temas como fontes de informação, freqüência de uso, importância e grau de dependência foram abordados. Por ser uma amostra relativamente pequena, os questionários foram aplicados pessoalmente pelos pesquisadores no período de abril e maio de 2008.

É importante destacar que, para esta pesquisa, foi considerado especificamente o ambiente competitivo dos empreendimentos pesquisados, composto exclusivamente pelos seus concorrentes instalados dentro e nas imediações do Shopping Popular Oiapoque, o que não descarta a importância de se considerarem as influências das demais variáveis ambientais em pesquisas futuras, como aquelas decorrentes das variáveis políticas, econômicas, tecnológicas e sociais que compõem o macroambiente organizacional, entre outras.

\section{APRESENTAC̣ÃO E ANÁLISE DOS DADOS}

Para a mensuração da freqüência de uso das fontes de informações foi desenvolvida uma escala do tipo Likert, na qual foram determinados três níveis de freqüência, conforme a percepção dos empresários responsáveis pela tomada de decisão estratégica: Baixa (entre 1 e 10 vezes por semana), Média (entre 11 e 20 vezes por semana) e Alta (acima de 20 vezes por semana). A tabela 1 apresenta, então, os dados compilados e extraídos dos questionários aplicados aos oito empresários instalados nas proximidades do Shopping Popular Oiapoque, na região central de Belo Horizonte.

TABELA 1

Freqüência de uso das fontes de informação

\begin{tabular}{|c|c|c|c|c|}
\hline & \multirow{2}{*}{ Fontes de Informação } & \multicolumn{3}{|c|}{ Freqüência de Uso } \\
\hline & & Baixa & Média & Alta \\
\hline $\mathrm{F} 1$ & Consumidores que compram no Oiapoque & $0 \%$ & $13 \%$ & $88 \%$ \\
\hline $\mathrm{F} 2$ & Consumidores que não compram no Oiapoque & $38 \%$ & $38 \%$ & $25 \%$ \\
\hline F3 & Comerciantes não concorrentes (fora do Oiapoque) & $50 \%$ & $38 \%$ & $13 \%$ \\
\hline F4 & Comerciantes não concorrentes (dentro do Oiapoque) & $75 \%$ & $0 \%$ & $25 \%$ \\
\hline F5 & Comerciantes concorrentes (fora do Oiapoque) & $13 \%$ & $13 \%$ & $75 \%$ \\
\hline F6 & Comerciantes concorrentes (dentro do Oiapoque) & $13 \%$ & $0 \%$ & $88 \%$ \\
\hline F7 & Funcionários de comércios não concorrentes (fora do Oiapoque) & $63 \%$ & $13 \%$ & $25 \%$ \\
\hline F8 & Funcionários de comércios não concorrentes (dentro Oiapoque) & $50 \%$ & $25 \%$ & $25 \%$ \\
\hline F9 & Funcionários de comércios concorrentes (fora do Oiapoque) & $13 \%$ & $38 \%$ & $50 \%$ \\
\hline F10 & Funcionários de comércios concorrentes (dentro Oiapoque) & $13 \%$ & $38 \%$ & $50 \%$ \\
\hline F11 & Funcionários da própria empresa & $0 \%$ & $25 \%$ & $75 \%$ \\
\hline F12 & Fornecedores de comércios não concorrentes (fora Oiapoque) & $38 \%$ & $38 \%$ & $25 \%$ \\
\hline F13 & Fornecedores de comércios não concorrentes (dentro Oiapoque) & $50 \%$ & $38 \%$ & $13 \%$ \\
\hline F14 & Fornecedores de comércios concorrentes (fora Oiapoque) & $13 \%$ & $13 \%$ & $75 \%$ \\
\hline F15 & Fornecedores de comércios concorrentes (dentro Oiapoque) & $0 \%$ & $38 \%$ & $63 \%$ \\
\hline F16 & Fornecedores da própria empresa & $13 \%$ & $0 \%$ & $88 \%$ \\
\hline F17 & Mídia eletrônica (Internet) & $25 \%$ & $13 \%$ & $63 \%$ \\
\hline F18 & Ofertas anunciadas em tablóides, folders, outdoors etc. (em papel) & $25 \%$ & $25 \%$ & $50 \%$ \\
\hline F19 & Jornal do bairro (região) & $38 \%$ & $38 \%$ & $25 \%$ \\
\hline $\mathrm{F} 20$ & Jornais de grande circulação & $38 \%$ & $13 \%$ & $50 \%$ \\
\hline $\mathrm{F} 21$ & Informativos de entidades do comércio (CDL, entre outras) & $25 \%$ & $50 \%$ & $25 \%$ \\
\hline $\mathrm{F} 22$ & Rádio e televisão & $13 \%$ & $25 \%$ & $63 \%$ \\
\hline
\end{tabular}

Fonte: dados da pesquisa ( $\mathrm{n}=8$ empresários). 
A partir da análise dos dados compilados, verifica-se que as fontes "consumidores que compram no Oiapoque (88\%), comerciantes concorrentes que atuam fora (75\%) e dentro do Oiapoque (88\%), funcionários do próprio estabelecimento (75\%), fornecedores dos estabelecimentos concorrentes atuantes fora (75\%) e dentro do Oiapoque (63\%), mídia eletrônica - internet, rádio e televisão (63\%) e, finalmente, as fontes impressas como os jornais de grande circulação e as ofertas anunciadas em folders, tablóides, outdoors, entre outros (50\%)" foram as fontes mais indicadas (ou monitoradas) pelos comerciantes pesquisados.

Entretanto, é importante destacar que algumas fontes não são muito utilizadas pelos comerciantes para subsidiar as suas decisões estratégicas, como, por exemplo, os comerciantes não concorrentes que atuam dentro (75\%) e fora (50\%) do Oiapoque, os funcionários de comércios não concorrentes que atuam fora (63\%) e dentro (50\%) do Oiapoque e os fornecedores dos comércios não concorrentes que atuam dentro do Oiapoque (50\%).
A análise desses dados revela, até com certa lógica, a baixa atenção dada pelos comerciantes às fontes de informações que não afetam diretamente o desempenho de seus negócios, apesar de os mesmos não excluírem totalmente o uso de tais fontes de informações na consecução de suas estratégias de negócios.

Uma primeira sugestão de pesquisa que surge nesse momento parte da necessidade de se identificarem os fatores que contribuem para esse pouco interesse dos comerciantes pesquisados em relação a tais fontes de informações. Será que os comerciantes não concorrentes e os seus respectivos fornecedores não têm informações de interesse para os comerciantes pesquisados em suas decisões estratégicas? Se têm, quais seriam essas informações? E como elas podem reduzir os riscos de fracasso e aumentar a eficácia das decisões tomadas?

Com vista a melhor entendimento da freqüência de uso das fontes de informações para a tomada de decisão estratégica, a tabela 2 foi construída para verificar a

TABELA 2

Importância das fontes de informação para a tomada de decisão

\begin{tabular}{clccc}
\hline & \multicolumn{1}{c}{ Fontes de Informação } & \multicolumn{2}{c}{ Freqüência de Uso } \\
& & Baixa & Média & Alta \\
\hline F1 & Consumidores que compram no Oiapoque & $0 \%$ & $13 \%$ & $88 \%$ \\
F2 & Consumidores que não compram no Oiapoque & $38 \%$ & $38 \%$ & $25 \%$ \\
F3 & Comerciantes não concorrentes (fora do Oiapoque) & $63 \%$ & $25 \%$ & $13 \%$ \\
F4 & Comerciantes não concorrentes (dentro do Oiapoque) & $75 \%$ & $0 \%$ & $25 \%$ \\
F5 & Comerciantes concorrentes (fora do Oiapoque) & $13 \%$ & $13 \%$ & $75 \%$ \\
F6 & Comerciantes concorrentes (dentro do Oiapoque) & $13 \%$ & $13 \%$ & $75 \%$ \\
F7 & Funcionários de comércios não concorrentes (fora do Oiapoque) & $63 \%$ & $13 \%$ & $25 \%$ \\
F8 & Funcionários de comércios não concorrentes (dentro Oiapoque) & $63 \%$ & $13 \%$ & $25 \%$ \\
F9 & Funcionários de comércios concorrentes (fora do Oiapoque) & $13 \%$ & $38 \%$ & $50 \%$ \\
F10 & Funcionários de comércios concorrentes (dentro Oiapoque) & $13 \%$ & $38 \%$ & $50 \%$ \\
F11 & Funcionários da própria empresa & $0 \%$ & $13 \%$ & $88 \%$ \\
F12 & Fornecedores de comércios não concorrentes (fora Oiapoque) & $50 \%$ & $38 \%$ & $13 \%$ \\
F13 & Fornecedores de comércios não concorrentes (dentro Oiapoque) & $50 \%$ & $38 \%$ & $13 \%$ \\
F14 & Fornecedores de comércios concorrentes (fora Oiapoque) & $0 \%$ & $13 \%$ & $88 \%$ \\
F15 & Fornecedores de comércios concorrentes (dentro Oiapoque) & $0 \%$ & $25 \%$ & $75 \%$ \\
F16 & Fornecedores da própria empresa & $0 \%$ & $13 \%$ & $88 \%$ \\
F17 & Mídia eletrônica (Internet) & $25 \%$ & $13 \%$ & $63 \%$ \\
F18 & Ofertas anunciadas em tablóides, folders etc. (em papel) & $25 \%$ & $25 \%$ & $50 \%$ \\
F19 & Jornal do bairro (região) & $38 \%$ & $25 \%$ & $38 \%$ \\
F20 & Jornais de grande circulação & $38 \%$ & $13 \%$ & $50 \%$ \\
F21 & Informativos de entidades do comércio (CDL, entre outras) & $38 \%$ & $25 \%$ & $38 \%$ \\
F22 & Rádio e televisão & $13 \%$ & $25 \%$ & $63 \%$ \\
\hline
\end{tabular}

Fonte: dados da pesquisa ( $\mathrm{n}=8$ empresários) 
importância dada pelos decisores estratégicos a cada uma dessas fontes. A premissa básica é a de que, quanto maior for a freqüência de uso de uma fonte de informação, maior será a sua importância, na percepção do decisor, para a tomada de decisão estratégica. A tabela 2 compila, então, os principais dados coletados sobre a importância de uma fonte de informação para a tomada de decisão estratégica.

A partir da análise dos dados da tabela 2, verifica-se que as fontes "consumidores que compram no Oiapoque (88\%), comerciantes concorrentes dentro e fora do Oiapoque (75\%), funcionários da própria empresa (88\%), fornecedores de comércios concorrentes dentro (75\%) e fora do Oiapoque (88\%), fornecedores de própria empresa (88\%), internet, rádio e televisão (63\%) e funcionários dos concorrentes - dentro e fora do Oiapoque - jornais de grande circulação e ofertas em tablóides, folder, entre outros (50\%)" apresentaram grande importância para os comerciantes em suas decisões, o que corrobora os dados obtidos na tabela 1 .

A mesma tendência se verificou nas fontes menos utilizadas pelos comerciantes para subsidiar as suas decisões, como, por exemplo, os comerciantes não concorrentes que atuam dentro e fora do Oiapoque (63\%) e os fornecedores de comércios não concorrentes que atuam dentro e fora do Oiapoque (50\%). Assim, a segunda sugestão para futuras pesquisas se refere à necessidade de mensurar e analisar as possíveis correlações existentes entre tais fontes de informações.

Analisadas individualmente a freqüência de uso e a importância das fontes de informações para a tomada de decisão estratégica, torna-se necessário, neste momento, mensurar o nível de dependência dos decisores em relação a tais fontes de informações. Para esta pesquisa, entenda-se por nível de dependência a relação existente entre a freqüencia de uso e o grau de importância das fontes de informações utilizadas no processo decisório. Assim, quanto maior a freqüência de uso e a importância de uma fonte de informação, maior será a dependência do decisor em relação a ela. Porém, se a fonte de informação é pouco acionada e a mesma tem pouca ou nenhuma importância para a eficácia da decisão, menor será a dependência do decisor em relação a tal fonte de informação.

Pela análise conjunta das tabelas 1 e 2, chega-se ao grau de dependência do decisor estratégico em relação às fontes de informações disponíveis e/ou utilizadas por ele para a tomada de decisão. Dessa maneira, em situação de elevada dependência, torna-se necessário manter um canal que promova a coleta de informações de tais fontes de maneira rápida, precisa e confiável, possibilitando, assim, uma tomada de decisão com menores riscos de falhas ou insucessos.

A partir da compilação dos dados constantes das tabelas 1 e 2, o gráfico 1, a seguir, foi construído. Pela sua análise, constata-se que para $88 \%$ dos decisores estratégicos, os seus fornecedores e os consumidores que compram no Oiapoque são as suas principais fontes de informação para a tomada de decisão estratégica. Fontes como os concorrentes instalados dentro do Oiapoque, os funcionários da própria empresa e os fornecedores dos concorrentes que atuam fora do Oiapoque também apresentaram níveis significativos de dependência por parte dos decisores.

Algumas fontes, apesar de não apresentarem resultados tão expressivos, também merecem destaque. Entre as principais, encontram-se os funcionários dos concorrentes, localizados dentro e fora do Oiapoque, a internet, o rádio, a televisão, os jornais de grande circulação e as ofertas anunciadas em outdoors, folders e tablóides. Finalmente, as demais fontes que não apresentaram resultados expressivos estão demonstradas no gráfico 2, a seguir. 
Monitoramento ambiental e fontes de informação para a tomada de decisão estratégica: o caso dos varejos formais instalados nas imediações do shopping popular Oiapoque em Belo Horizonte

GRÁFICO 1

Nível de dependência em relação às fontes de informações

(Freqüência de uso versus importância percebida)

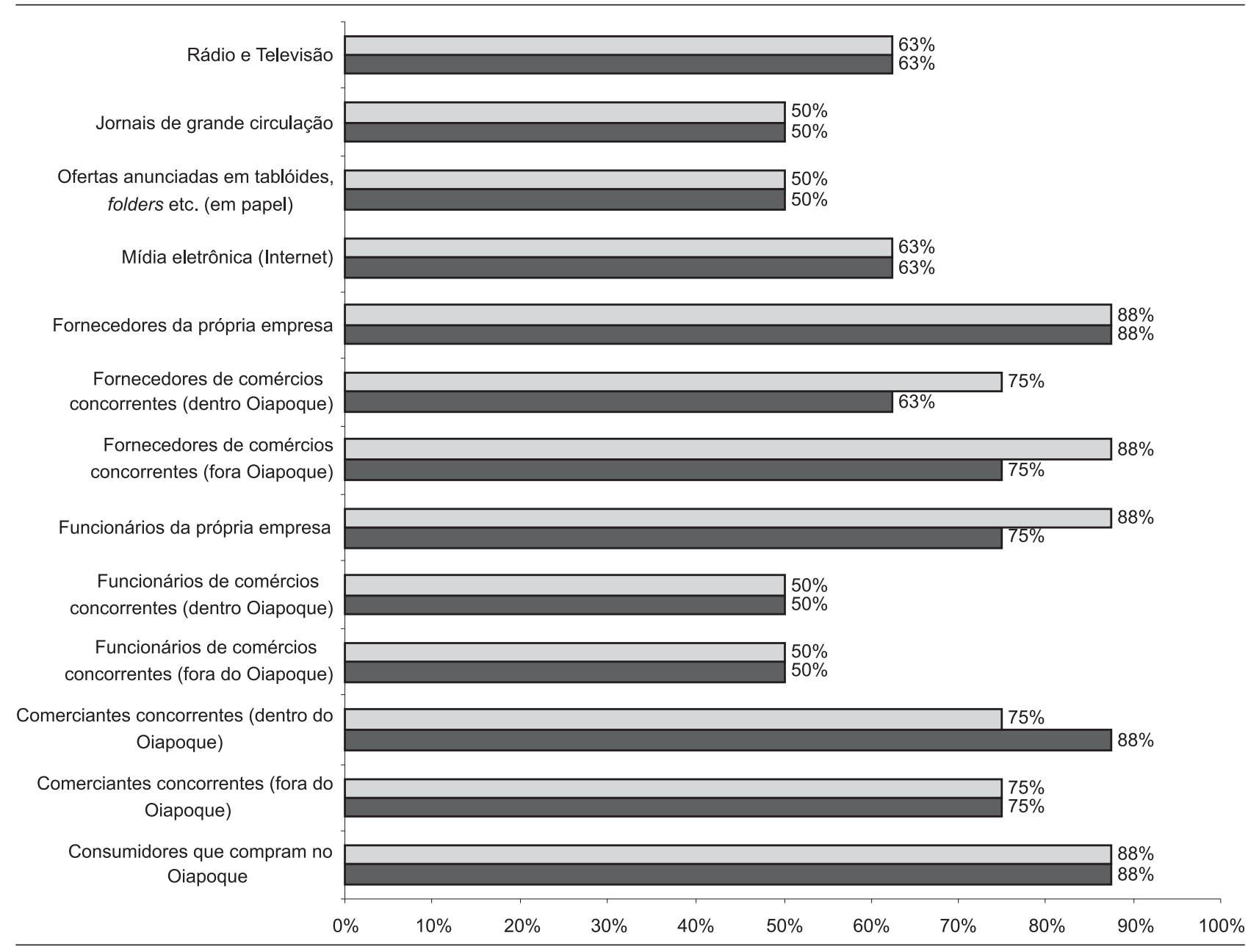

Fonte: dados compilados da tabela 1 e tabela 2. 
GRÁFICO 2

Fontes de informações com menores índices de dependência (freqüência de uso versus importância)

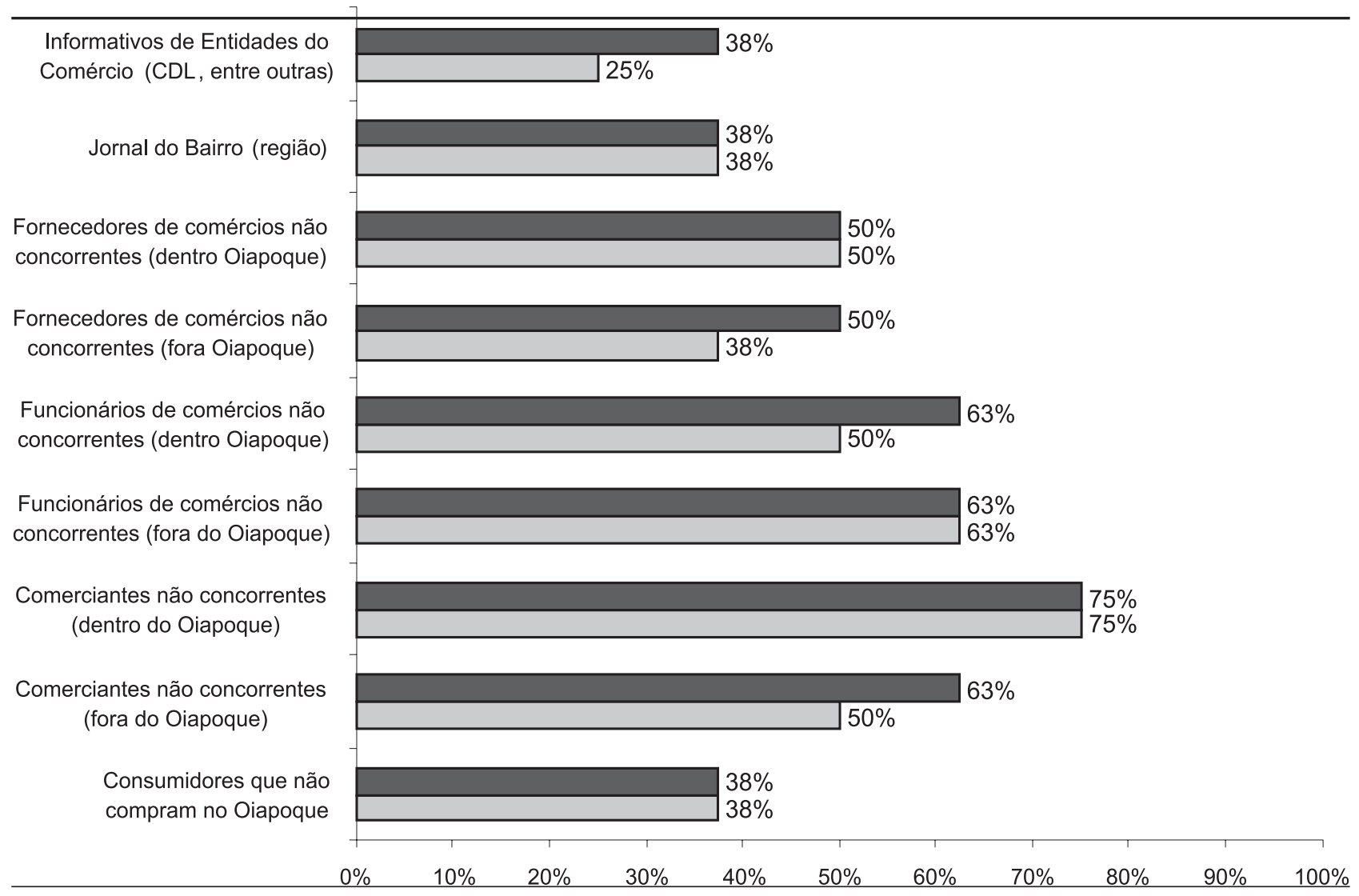

Fonte: dados compilados da tabela 1 e tabela 2 .

Em contraste em relação ao gráfico 1, o gráfico 2 apresenta as fontes de informações com menores índices de dependência por parte dos decisores para a tomada de decisão estratégica. Para 75\% deles, a fonte "comerciantes não concorrentes dentro do Oiapoque" apresentou o menor nível de freqüência de uso e de importância dada por parte dos pesquisados.

Essa conclusão pode decorrer de dois fatores principais. Primeiro, porque tais empreendimentos podem não concorrer direta e/ou indiretamente com os produtos e/ou serviços oferecidos pelos comerciantes pesquisados e, segundo, esses comércios estão dentro do Oiapoque, o que pode dificultar o processo de monitoramento por parte dos decisores.

Outra fonte que apresentou um resultado expressivo foi "funcionários de comércios não concorrentes localizados fora do Oiapoque". Para 63\% dos pesquisados, tais funcionários não são utilizados como fontes de informação e têm pouca ou nenhuma importância para a tomada de decisão. E, por fim, as demais fontes foram consideradas pouco expressivas no processo decisório, em especial os consumidores que não compram no Oiapoque, os fornecedores de comércios não concorrentes que atuam dentro e/ou fora do Oiapoque, o jornal de bairro e os informativos de entidades do comércio, como da CDL, associações Comerciais, entre outros.

A partir dessas conclusões, uma terceira sugestão de pesquisa deve partir da necessidade de se compreender o porquê de essas fontes impessoais (ou escritas) não serem utilizadas por esses comerciantes, uma vez que elas normalmente representam fontes importantes de informações sobre o comércio local. 


\section{CONSIDERAC̣ÕES FINAIS E RECOMENDAC̣ÕES}

Pesquisas sobre monitoramento ambiental e fontes de informação têm sido cada vez mais freqüentes na literatura. Desde os estudos dos autores contingenciais, do início do século passado, que pesquisaram a influência do ambiente externo sobre a tecnologia, a estrutura e as estratégias organizacionais, até os dias de hoje, percebe-se que o ambiente externo ainda tem despertado especial atenção para muitos pesquisadores de diversos campos da ciência, especialmente para aqueles ligados às ciências administrativas, organizacionais, informacionais e biológicas. Impulsionados pelo o acirramento da competição que se verifica a cada ano, (PORTER, 1980; HITT et alii, 2003), temas como monitoramento ambiental, fontes de informação, estratégia empresarial e comportamento informacional, dentre outros, têm despertado especial atenção na agenda de acadêmicos e empresários nos quatro cantos do planeta.

E no contexto das micro e pequenas empresas localizadas nas imediações do Shopping Popular Oiapoque, esses temas propiciaram grande oportunidade de pesquisa voltada para a análise do comportamento informacional dos decisores estratégicos de tais empreendimentos. Assim, verificou-se que o acirramento da competição local tem impactado profundamente o modo de como esses empresários usam a informação para a tomada de decisão estratégica.

A análise dos dados revelou que os empresários têm grande dependência das fontes pessoais internas, como os funcionários da própria empresa, como também em relação aos seus fornecedores e consumidores que também freqüentam o shopping Oiapoque. Os concorrentes que atuam dentro do Shopping também foram considerados fontes de alta dependência. Nesse caso, sugere-se a manutenção de estruturas que facilite a aquisição, o armazenamento e o processamento e distribuição das informações provenientes de tais fontes de informação aos tomadores de decisões estratégicas, buscando mantê-los sempre informados e atualizados acerca dos fatos, eventos, relacionamentos e tendências que acontecem em seus ambientes de negócios.
Entretanto, para as demais fontes de informações investigadas por esta pesquisa, as quais apresentaram baixos índices de dependência dos decisores para as suas tomadas de decisões estratégicas, fica a sugestão de redução (não- extinção) da estrutura disponibilizada para a sua monitoração, sem perder de vista a evolução de tais fontes ao longo do tempo.

Em termos conclusivos, constata-se que o acirramento da competição tem grande impacto sobre o modo de como os micro e pequenos empresários usam a informação para a tomada de decisão estratégica (OLIVEIRA, 2007). A busca por melhores posições nos mercados competitivos demanda uma postura proativa orientada para o monitoramento do movimento dos competidores atuais e potenciais.

Assim, torna-se necessário que os gestores tenham sempre à sua disposição informações rápidas, precisas e confiáveis que lhes proporcionem as condições necessárias para um processo de tomada de decisão estratégica cada vez mais eficiente e eficaz, aumentando as chances de sobrevivência e o crescimento de suas organizações nos mercados em que atuam ao longo do tempo, evitando e/ou neutralizando as ameaças e buscando novas oportunidades de negócios.

Por fim, por ser uma pesquisa de caráter exploratório, algumas limitações e recomendações se fazem necessárias nesse momento. Primeiro recomenda-se a utilização de uma amostra maior que represente com maior grau de confiabilidade as características da população de todos os empreendimentos localizados nas imediações dos shoppings populares, não apenas de Belo Horizonte, mas de todo o Brasil e, talvez, do mundo. Segundo, é importante investigar as possíveis correlações existentes entre o perfil do empreendedor, o seu comportamento informacional, as fontes de informações utilizadas e as estratégias empresariais adotadas, o que não foi abordado por esta pesquisa. E, finalmente, ressalta-se que, apesar de algumas limitações metodológicas, esta pesquisa apresentou contribuições significativas para melhor compreensão dos temas em questão na medida em que evidenciou algumas características do comportamento informacional dos empresários pesquisados e a difícil situação que enfrentam em seus mercados competitivos.

Artigo submetido em 25/09/2008 e aceito em 29/12/2008. 
Monitoramento ambiental e fontes de informação para a tomada de decisão estratégica: o caso dos varejos formais instalados nas imediações do shopping popular Oiapoque em Belo Horizonte

\section{REFERÊNCIAS}

1. AGUILAR, F. J. Scanning the business environment. New York: The Macmillan Company, 1967.

2. AlbuQUerQue, A. Pesquisa dos alunos da FAMC analisa comportamento de comerciantes e consumidores de shopping popular. 2007. Disponivel em: 〈http://www.mcampos.br/JORNAL/n113/ pag07.htm>. Acesso em: 10 jun. 2008.

3. ANDREWS, K. R. The concept of corporate strategy. Homewood: Richard D. Irwin, 1980

4. AUSTER, E.; CHOO, C. W. Environmental scanning by CEOs in two canadian industries. Journal of the American Society for Information Science, v. 44, n. 4, p. 194-203, 1993.

5. BARBOSA, R. R. Inteligência empresarial: uma avaliação de fontes de informação sobre o ambiente organizacional externo. Datagrama Zero - Revista de Ciência da Informação, v. 3, n. 6, dez. 2002.

6. _. Monitoração ambiental: uma visão interdisciplinar, Revista de Administração, v. 32, n. 4, p. 42-53, out./dez. 1997.

7. BASTOS, Jaime S. Y. Monitoração ambiental no setor de tecnologia da informação das regiões sul e sudeste do Brasil: um estudo sobre fontes de informação e aspectos ambientais. 2005. 119f. Dissertação (Mestrado em Ciência da Informação) - Escola de Ciência da Informação, UFMG, Belo Horizonte, 2005.

8. CERTO, Samuel, C. Administração moderna. São Paulo: PrenticeHall, 2003.

9. CHANDLER, A. Strategy and structure. Cambrige, MA: MIT Press, 1962.

10. CHOO, C.W.; AUSTER, E. Environmental scanning: acquisition and use of information by managers. Annual Review of Information Science and Technology, v. 28, p. 279-314, 1993.

11. ______. A organização do conhecimento: como as organizações usam a informação para criar significado, construir conhecimento e tomar decisões. São Paulo: Senac, 2003.

12. COllis, J.; HUSSEY, R. Pesquisa em administração. 2. ed. Porto Alegre: Bookman, 2005.

13. DAFT, R. L. Organizações: teorias e projetos. São Paulo: Pioneira Thomson Learning, 2002.

14. environmental characteristics, and company performance: an empirical study. Strategic Management Journal, v. 9, n. 2, p. 123-139, 1988.

15. D'AVENI, Richard. Hipercompetição. Rio de Janeiro: Campus, 1995.

16. DRUCKER, Peter. F. The information executives truly need. Harvard Business Review, Jan./Feb. 1995.

17. . Desafios gerenciais para o século XXI. São Paulo: Pioneira, 1999.

18. DUNCAN, R. Characteristics of organizational environments and perceived environmental uncertainty. Administrative Science Quarterly, v. 17, n. 3, p. 313-327, 1972.

19. HAMBRICK, D. C. Environmental scanning and organizational strategy. Strategic management Journal, v. 13, n. 2, p. 44-49, 1982.
20. HITT, Michael A., IRELAND, R. Duane, HOSKISSON, Robert E. Administração estratégica. São Paulo: Bookman, 2003.

21. KATZ, D., KAHN, R. L. Psicologia das organizações. São Paulo: Atlas, 1970.

22. KOTLER, P. Administração de marketing: análise, planejamento, implementação e controle. 10. ed. São Paulo: Atlas, 2000.

23. MILES, Raymond E.; SNOW, Charles C. Organizational strategy, structure, and process. New York: Mc Graw-Hill, 1978.

24. MINTZBERG, H. Criando organizações eficazes. 2. ed. São Paulo: Atlas, 2003

25. Review, v. 72, n. 1, p. 107-114, 1994.

26. Bookman, 2001

KUEN, J. B. O Processo da estratégia. 3. ed. Porto Alegre:

27. NADLER, D. A. et al. Arquitetura organizacional: a chave para a mudança empresarial. Rio de Janeiro: Campus, 1993.

28. NETO, J. S. Feirão de ofertas. Revista Veja On-Line. Disponivel em: <http://veja.abril.com.br/150798/p_098.html>. Acesso em: jan. 2008.

29. NONAKA, I.; TAKEUCHI, H. Criação do conhecimento na empresa. Rio de Janeiro: Campus, 1997.

30. OLIVEIRA, P. H. Um estudo sobre a arquitetura organizacional da Polícia Militar do Estado de Minas Gerais com proposta de aproveitamento no setor industrial. In: SEMINÁRIO DE SISTEMAS INDUSTRIAIS E AUTOMAC̣ÃO, 1., 2006, Belo Horizonte. Anais... Belo Horizonte: CEFET/MG, 2006. v. 1.

31. ; AlmeidA, P. P., LACERDA, J. M. Práticas de inteligência competitiva no setor varejista de Belo Horizonte: um estudo exploratório. In: CONGRESSO INTERNACIONAL DE ADMINISTRAC̣ÃO, 20., 2007, Ponta Grossa. Anais... Ponta Grossa: UEPG, 2007.

32. PORTER, M. Competitive strategy: techniques for analyzing industries and competitors. New York: The Free Press, 1980.

33. SIMON, H. A. Comportamento administrativo: estudo dos processos decisórios nas organizações administrativas. 2. ed. Rio de Janeiro: Fundação Getúlio Vargas, 1965.

34. SCHERMERHORN, John, R. Administração. Rio de Janeiro: LTC, 2007.

35. SOBRAL, Filipe; PECI, Alketa. Administração: teoria e prática no contexto brasileiro. São Paulo: Prentice-Hall, 2008.

36. STEINER, G. A. Strategic planning. New York: The Free Press, 1979.

37. SUTTON, H. Competitive intelligence. New York: The Conference Board, 1988.

38. Inteligência empresarial: uma avaliação de fontes de informação sobre o ambiente organizacional externo. Datagrama Zero - Revista de Ciência da Informação, v. 3, n. 6, dez. 2002. 